\title{
Easily Accessible Experiments Demonstrating Interference
}

\author{
Robert Polak \\ Loyola University Chicago, rpolak@luc.edu
}

Nicolette Fudala

Loyola University Chicago

Jason T. Rothchild

Loyola University Chicago

Marcin Zelek

Loyola University Chicago

Follow this and additional works at: https://ecommons.luc.edu/physics_facpubs

Part of the Physics Commons

\section{Recommended Citation}

Polak, Robert; Fudala, Nicolette; Rothchild, Jason T.; and Zelek, Marcin, "Easily Accessible Experiments Demonstrating Interference" (2016). Physics: Faculty Publications and Other Works. 48.

https://ecommons.luc.edu/physics_facpubs/48

This Article is brought to you for free and open access by the Faculty Publications and Other Works by Department at Loyola eCommons. It has been accepted for inclusion in Physics: Faculty Publications and Other Works by an authorized administrator of Loyola eCommons. For more information, please contact ecommons@luc.edu.

\section{(c) (i) $\Theta$}

This work is licensed under a Creative Commons Attribution-Noncommercial-No Derivative Works 3.0 License. (c) Robert D. Polak, et al. 2016 


\section{Easily accessible experi- ments demonstrating interference}

\author{
Robert D. Polak, Nicolette Fudala, Jason T. \\ Rothchild, Sam E. Weiss, and Marcin Zelek, \\ Department of Physics, Loyola University Chicago, Chicago, IL
}

$\mathrm{W}$ e developed two experiments for demonstrating the interference of waves using commonly available tools and materials. The interference of sound can be observed in an outdoor setting using a smartphone with a free application, a USB power pack, and a pair of computer speakers. The coherent sound waves from the two separated speakers create easily identifiable points of destructive interference. The interference of light can be demonstrated by cutting lines in electric tape adhered to a microscope slide and using a coherent light source such as a laser pointer. The single- and double-slit interference patterns can be observed on a screen placed some distance from the source.

For interference of sound, we downloaded Audio Function Generator ${ }^{1}$ for an Apple iPhone 6 using iOS and Waveform Generator Demo ${ }^{2}$ for a Samsung Galaxy S4 using Android OS. Both of these applications generated sinusoidal waveforms over a wide range of audio frequencies. The phone acted as an audio source for two Dell computer speakers (Model \#A225) that were powered by a PowerGen External Battery Pack (Model \# PGMPP12000). The speakers were placed $85 \mathrm{~cm}$ apart on a cart approximately $1 \mathrm{~m}$ above the ground outdoors in an open field (see Fig. 1). At a frequency of $800 \mathrm{~Hz}$, we were able to identify locations of destructive interference up to $15 \mathrm{~m}$ from the speakers with normal ambient noise present. To identify the interference pattern, students were given stake flags ${ }^{3}$ to place in the ground at points of destructive interference. To create a clear interference pattern, students were directed to walk in straight lines parallel to a line connecting the two speakers, as shown in Fig. 2. The distance from the speakers was increased by about $1 \mathrm{~m}$ for each successive line, creating a pattern of destructive interference consistent with theory. This experiment also works well on a blacktop surface with chalk. Additionally, by using two different frequencies $(400 \mathrm{~Hz}$ and $1600 \mathrm{~Hz}$ ), we were able to observe the distance between lines of destructive interference increasing and decreasing respectively. Finally, at $400 \mathrm{~Hz}$, we measured the distance from each speaker, given by $d_{1}$ and $d_{2}$, to a nearby location of destructive interference along one of the two center lines. Noting that the difference in path length $\left(\left|d_{2}-d_{1}\right|\right)$ for this point would be equal to half the wavelength, we were able to determine the wavelength of the sound to be $0.914 \mathrm{~m}$ and the speed of sound to be $366 \mathrm{~m} / \mathrm{s}$, within $7 \%$ of the accepted value for standard temperature and pressure.

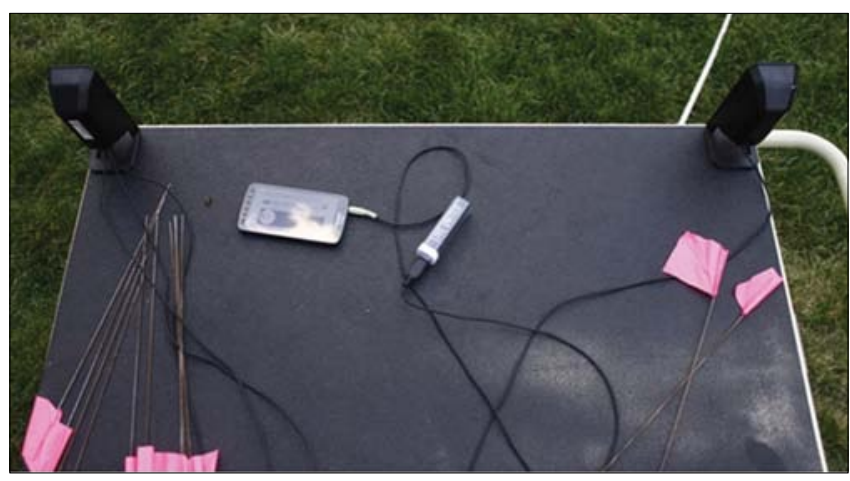

Fig. 1. The two speakers are placed on a cart about $1 \mathrm{~m}$ above the ground. The signal is provided by a smartphone, and the speakers are powered by a battery pack. Stake flags are also shown on the cart.

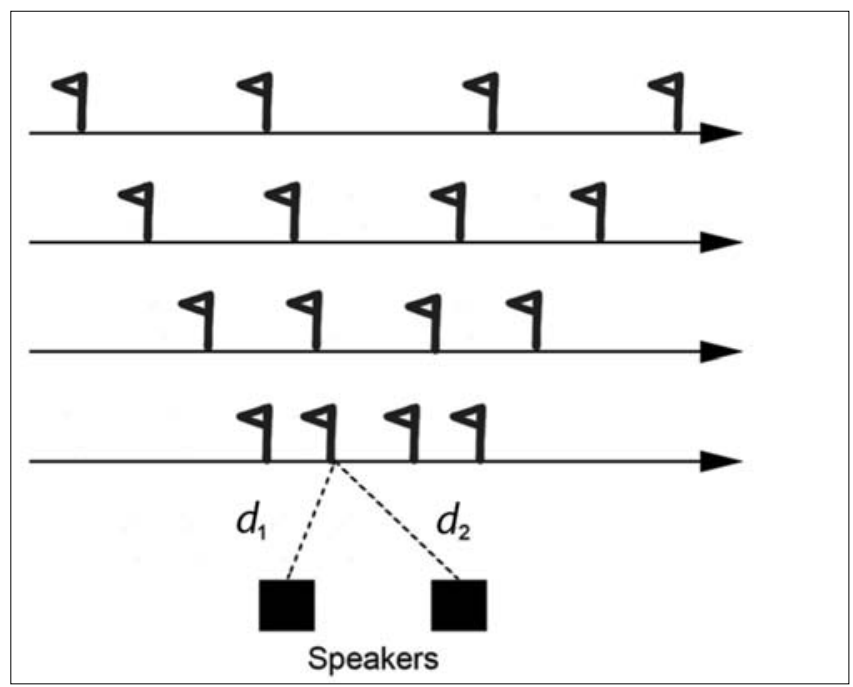

Fig. 2. Students follow the path shown by the arrowed lines, placing stake flags at points of destructive interference. Each arrowed line is parallel to a line connecting the two speakers. By following the paths shown and continually increasing the distance from the two speakers, a clear interference pattern, shown by the flags, is formed. The wavelength of the sound wave is determined by measuring the distance from each speaker, denoted by $d_{1}$ and $d_{2}$, to a nearby flag.

To demonstrate interference of light, a single or double slit can be created by adhering black electrical tape to a typical microscope slide (see Fig. 3). With either a single razor or two razors lined up and taped together, we cut slits into the tape. We found that stretching the tape as it is adhered to the slide allows for the cuts to separate, creating thin slits. Using fresh razor blades to make the cuts yielded the best results. A laser source $^{4}$ was aligned to project light through a single or double slit on the microscope slide. To ensure stability and maintain proper alignment, each piece was held in place on a wooden board using modeling clay. A single- or double-slit pattern was visible on a screen about $3 \mathrm{~m}$ behind the slits (see Fig. 4). To determine the wavelength of light, we measured the average distance between constructive interference points over 
many peaks as well as the distance to the screen. The distance between the slits was measured via optical microscopy. Using formulas for double slit interference with this data, we determined the wavelength of light for the three different sources to within $8 \%$ of the accepted values. It is important to note the limited lifetime of the slits, as the tape stretches over time and the quality of the slits degrades.

These experiments would be useful in many settings, espe-

cially those with limited financial resources. The items used are commonly available to many physics instructors.

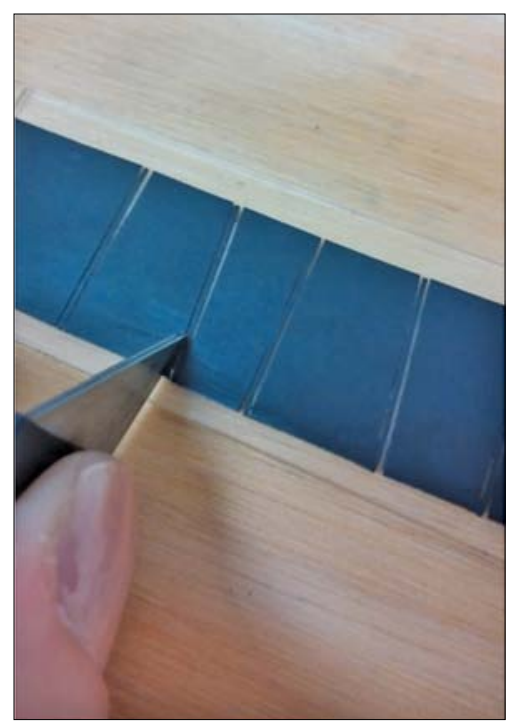

Fig. 3. A double-slit pattern is cut into black electrical tape adhered to a microscope slide using two razor blades taped together.

\section{Fermi Questions}

Larry Weinstein, Column Editor

Old Dominion University, Norfolk, VA 23529; weinstein@odu.edu

\section{Duestion 1: Blow dart}

What is the maximum range of a blow dart (i.e., of a dart propelled from a tube by the force of human exhalation)? (The question was inspired [so to speak] by Tom Russel of Norfolk, VA.)

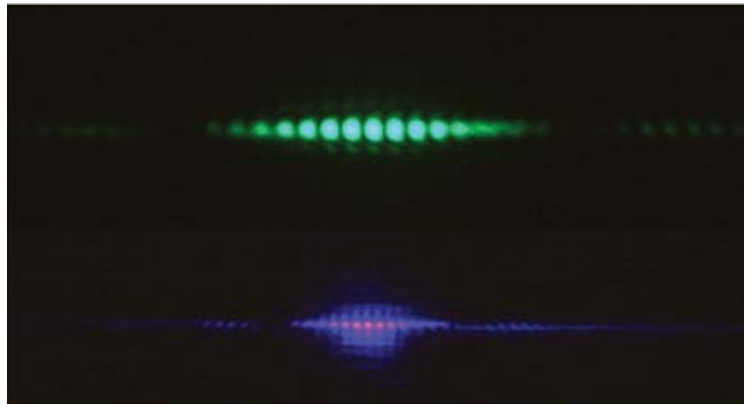

Fig. 4. The double-slit interference pattern of a green and violet laser source are projected onto a screen. The same double slit was used for both patterns.

\section{References}

1. Thomas Gruber, Audio Function Generator (Version 2.7.6), Mobile Application Software. Retrieved from http://itunes. apple.com, accessed Dec. 23, 2015.

2. Trono, Waveform Generator Demo (Version 1.5), Mobile Application Software. Retrieved from http://play.google.com/ store/apps/, accessed Dec. 23, 2015.

3. Stake flags are available at home improvement stores such as Lowe's, Home Depot, and Menards. They may be referred to as utility flags, irrigation flags, or marking flags.

4. We used 5-mW green and violet laser pointers and a pocket red laser pointer from American Science \& Surplus. 